\title{
An Analysis of Competition and Displacement of Business among Media Forms in the Advertising Media Market of Pakistan
}

\author{
Barira Bakhtawar*, Faiza Latif ${ }^{* *}$ and Asifa Kamal ${ }^{* * *}$
}

\begin{abstract}
The primary objective of this research is to ascertain the relationship between market shares of traditional and digital media in Pakistan by using the theoretical framework of the media niche theory. In order to achieve this objective, the study has tested different relationships between advertising market shares of media forms through various statistical techniques. The researchers have determined the overlaps and variabilities among the advertising market shares of media forms through ANOVA and Tukey's post hoc. In addition to this, Kendall tau's correlation has been used in order to analyze the effects of digital media on the advertising market share of traditional media. The simple linear regression method has also been used to find out if a viable relationship exists between media forms and advertising expenditure. The study findings have indicated that media forms are statistically significantly different in spending on advertisements. Tukey's Post Hoc test reveals that advertising expenditure of radio is significantly different from $T V$ and Print Media, but there is no significant difference between the expenditure of radio and digital media. It is also determined that a significant inverse relationship exists between advertisement spending on digital media and $T V$, and digital media and radio. However, a significant and positive relationship is found between digital media and print media, but with a very weak value of Kendall tau. Our study implies that traditional media is experiencing a downfall in the advertising media market, primarily due to the widespread advent of digital media in Pakistan.
\end{abstract}

Keywords: Media, digital media, advertising, market share, media niche theory, media economics.

JEL classification: E32, L1, M2, M3.

* PhD Scholar, Department of Mass Communication, Lahore College for Women University, Lahore, Pakistan.

** Assistant Professor, Department of Mass Communication, Lahore College for Women University, Lahore, Pakistan.

${ }^{* * *}$ Associate Professor, Department of Statistics, Lahore College for Women University, Lahore, Pakistan. 


\section{Introduction}

The media industry differs from other business industries primarily in terms of its dealing with creative individuals, and the uncertainty in demand that it experiences (Caves, 2000; Townley et al., 2009). Ultimately, media content is the end product that is created in order to attract a targeted group of consumers (Wicks et al., 2004). The idea is to maximize the ratings by giving the audience what they want, rather than what they need (Redmond, 2006), with the special influence of market structure (Dimmick \& McDonald, 2001). In today's competitive business environment, firms face uncertainty and several unforeseen challenges (Abbas et al., 2019), and business firms severely observe a crucial role in organizational innovation (Abbas et al., 2019). In this regard, an ability to cope with the ever-changing environment of the media industry, and use this change as a competitive advantage is crucial for every media organization (Albarran, 2006). The communication industry represents a successful form of organization that is a consolidation of innovation, audience demands, content production, monetary support, and a hierarchical structure within an organization that provides support to all the different functions that exist (Dimmick, 2002). The monetary support a media organization attains is typically received in the form of advertising market share. The success or failure of media organizations depends on the economic characteristics, which include debt levels, investments, and the productivity of their team, and the role of the human resources, which is evident through consumer choice, advertising budget allocations and the regulatory mechanisms (McChesney, 2008). Moreover, commercial media organizations meet their increasing costs by generating revenue through advertising share in the media market.

According to the media niche theory, there is a dynamic relationship among various media industries. This is so because they are dependent on the available environmental resources, and the number of industries present within the media ecosystem which qualifies to utilize the resources. Therefore, the study of available resources (total advertising budget), and their utilization (individual advertising market share of media industries) can very well contribute towards analyzing the intensity of competition within a media ecosystem, among various media industries. Every media organization exercises an active presence on the internet, making itself more open and accessible to the public. This means that these organizations are becoming a little bit of everything, as radio is broadcasting live videos of studio shows, TV shows are available through online forums, and newspapers are available through websites 
(McFadden, 2010). The world today is a global village that has been made even smaller through the advent of technology, by the frequent and common usage of social media (Abbas et al., 2019). Internet users have increased from 414 million in 2000, 665 million in 2002, to over 4.574 billion by December 31, 2019, globally (Lebni et al., 2020). Keeping this data in check, it can be concluded that the internet and digital media now act as a mass medium, as the internet exhibits qualities of traditional mass media by the production of mass appeal content (Napoli, 1998). The growth of mass media is dependent on the overall economy of a country, and there is a budgetary relationship between the media industry and the Government of Pakistan, which is a way of controlling the content and economics of the media industry.

Digital media has been categorized as "nascent media", while traditional media as TV, radio and print media, as guided by the media niche theory. This research, therefore, has used secondary data from Gallup and Aurora. Also, the current research area has limited studies available which have been discussed in section 2.1. No advertising market share research making use of the media niche theory has been conducted to date for Pakistan's media industry. It is noteworthy that the media industry of Pakistan has been going through dynamic changes, due to the digitalization of media forms. Therefore, the theoretical framework of the media niche theory for achieving the study objectives can be a fruitful attempt.

This study aims to achieve multiple objectives. The first one of these is to thoroughly examine the variability in the advertising market shares of various media forms. In addition to this, another objective is to analyze the effect of nascent media (digital) on the advertising market shares of traditional media (TV, radio, print). Also, this study aims to determine the relationship between media forms and media expenditure, and also identify which traditional media industry has been affected the most in terms of its advertising market share in a changing advertising media market, due to the arrival of nascent media.

When discussing the significance of the study, we can observe that a study of new media's influence and relationship, in comparison with the old media can provide valuable insights in mapping out the media ecosystem. Therefore, this study provides concrete data about the positioning of traditional and digital audio media in the domain of advertising market share. In addition to this, this research is novel as it is the first one of its kind that has comprehensively analyzed the advertising share in the media market of Pakistan, thus revealing the patterns of 
relationship among them, thereby contributing towards the research in the media business. The study has led to the findings and guidelines that can help the stakeholders of the media industry more effectively in Pakistan. Moreover, the study contributes to the literature of media management and economics, which is a neglected field in Pakistan but still has prospects for growing as a specialized field in the coming decade.

\section{Literature Review}

\subsection{Media Niche Theory}

The study utilizes the framework that revolves around the media niche theory, in order to analyze the relationship between media forms in the advertising media market. The media niche theory was introduced, and applied for analysis in media by John Dimmick and Eric Rothenbuhler in 1984, then Carroll in 1985 (Carroll, 1985; Dimmick \& Rothenbuhler, 1984), and later on taken forward in 2002 by John Dimmick in his book Media competition and coexistence: The theory of the niche (Dimmick, 2002). It is noteworthy that the media niche theory suggests an ecological analysis of competition among media organizations (Hellman \& Soramäki, 1994). The concept of 'niche market' refers to a specialist company or industry. Therefore, it deals with the competition or co-existence of media organizations. According to the media niche theory, the competition or coexistence can be analyzed in any of the six major macro dimensions, including the gratifications obtained, gratification opportunities, content, consumer spending, time spent by consumers and advertising spending. These macro dimensions happen to have a deeper connection with each other, and the stability of the media market ultimately depends on the success achieved in advertising (Gabszewicz et al., 2006).

A common way of referring to the business of media organizations is to use the term 'market'. The market primarily depends on two elements, i.e., media products and geography (Albarran, 1996). Media products mainly include the programming and content offered by media organizations. According to Dimmick (2002), it is common knowledge that radio and print media have a narrow niche, while TV has a broader niche. In addition to this, radio and print media might have a larger share in the local advertising, as compared to TV, which is based mostly on the national advertising share. If the resources are limited in the environment i.e. there is no significant increase in the total advertisement spends every year, the entrance of a new competitor, i.e. digital media, may lead to tough competition. According to the media niche theory, competition can be 
minimized by increasing the possibility of growing the influx of resources, or niche differentiation, which will lead to the co-existence of all the media organizations. There can also be a partial displacement, or worse, a competitive exclusion which is rare among the media organizations.

Studies of competition, co-existence and displacement have been conducted in various macro dimensions of the different media forms in order to determine their positioning in the respective media ecosystem. The results differ largely based on the geographical boundaries where the research is being conducted and the overall strength of the media industry of that country (Albarran et al., 2007; Albarran \& Dimmick, 1993; J. Dimmick et al., 2004; J. W. Dimmick et al., 1992; W. Dimmick \& McDonald, 2000; Ferguson et al., 2007; Hoplamazian et al., 2018; Nelson \& Winter, 1982; Nielsen, 1998; Ries \& Ries, 2000). However, four important studies, particularly written in the domain of advertising macro dimensions, and using the framework of media niche theory, have been quoted as follows. The advertising income analysis from the years pertaining to 1928-1982 revealed a significant overlap between the TV and radio platforms (Dimmick \& Rothenbuhler, 1984), and in the 1960s, a significant niche overlap between TV and radio, and between TV and newspaper (Dimmick \& Rothenbuhler, 1984). The advertising market share analysis of the TV, radio and cable TV revealed that media pertaining to TV and cable had a high overlap, and that cable had been trying to invade the TV niche with high superiority during the 1980s. In addition to this, radio remained competitive but not at the level of TV (Dimmick et al., 1992). Another study focused on the diffusion of competition, in order to analyze the decline in the US newspaper advertising, and used the data from the Newspaper Association of America, Pew and Universal McCann. the results of this study revealed that there had been a long-term displacement of newspaper advertising due to diffuse competition (Dimmick, 2013).

\subsection{Nascent Media Evolution and Changing Advertising Business Models}

Some important studies conducted in the relevant research area of nascent and traditional media also suggest that the nascent industries keep on appearing due to 'Innovation' (Rogers, 1986; Stöber, 2004) and 'Diversification' (Napoli, 1998). Also, a nation's technological infrastructure proves to be of great importance when it comes to the growth of new media within the society (Lehman-Wilzig \& Cohen-Avigdor, 2004). The time-span of the adoption of new technology within a society has been measured to be roughly 30 years. In this period, the first decade usually contains the most excitement and exhilaration. Then, the second decade covers comprehensive 
technological advancement and business infiltration, while and the third decade consists of technological adaption through increased usage that infiltrates among the masses (Saffo, 1992).

In this regard, four stages of new media development were introduced, which primarily included the features pertaining to inauguration, institutionalization, defensiveness and adaptation of new technologies (Caspi, 1993). The competition for advertising among media organizations also have diverse effects on the program production, and the diversity among media products. This most comply includes the duplication of popular programs (Steiner, 1952), and competition in program schedules to gain access to the maximum amount of audience and advertising share (Cancian et al., 1995). A similar concept to understand displacement, as presented by media niche theory, has been referred to as 'Mediacide' (O'Brien, 1999). Moreover, the concepts of functional equivalence, functional differentiation and multiplicity were introduced as similar ideologies to media niche theory's competition, co-existence and convergence of media forms, respectively (Adoni \& Nossek, 2001). In today's media business environment, digital media appears as a nascent industry. Moreover, this media industry possesses the characteristics of being interactive through its click-through rates, and therefore its openness increases user involvement in the advertising process (Rosenkrans, 2009; Wen-jing, 2014). A new advertising model, in the age of media convergence, is in favor of more efficient and effective advertising (McPhillips \& Merlo, 2008). It has been suggested that new media has to look for its perfect business model, as it is going to determine the future of the media industry (Stöber, 2004). According to Dimmick (2002), in order to identify competition among industries, one has to look for similarities and differences. This overlap may also specify an index of competition (Hellman \& Soramäki, 1994). However, supporting evidence should also be gathered using various methods and other macro dimensions for a possibility of competition or displacement.

\section{Methodology}

\subsection{Media Landscape in Pakistan}

Before the advent of digital media in the advertising media market of Pakistan, TV captured the largest market share, being the generalist medium, while radio and print media maintained their stable shares in the media market. It was the year 2011-12 that marked the advent of digital media in the advertising market, which significantly affected the 
traditional media's market share. In this regard, $\mathrm{OOH}$ (out-of-home) advertising and brand activation rapidly developed with the arrival of digital marketing concepts, and started acquiring larger market advertising shares (Aurora, 2019). It is noteworthy that internet penetration in Pakistan stood at 35\% by January 2020 (Kemp, 2020). The usage of the internet and social media platforms is also giving an edge to outdoor and brand activation initiatives, which is posing a challenge to traditional media for getting advertisements, thereby giving rise to further competition in the industry.

The advertising market share of radio is directly connected to the listenership. In this context, $9 \%$ of the Pakistani population listens to radio (Gallup, 2017). As of now, a total number of 67 broadcasting units out of which 33 are mediumwave, seven are shortwave and 27 are FM stations are operating under the Pakistan Broadcasting Corporation. A total number of 75 commercial and 60 non-commercial (community) FM stations are operating in the country (PEMRA, 2021). Moreover, BBC Urdu confirmed shutting down its services on SW (shortwave) and MW (medium wave) in Pakistan, and shifted to FM and digital platforms for its famed news program "Sairbeen" in 2019 (BBC, 2019). However, though, Pakistan is still lagging in the adoption of more advanced digital forms of audio media (Tahir, 2002). But streaming audio, radio social media apps, and web radio have gradually shown popularity in Pakistan, as the access to audio streaming of radio through websites and social media apps stand at a solid 85\% (GroupM, 2018).

According to the recent figures by PEMRA (2021), 119 Satellite TV Channels are operating in Pakistan. YouTube, Netflix and Dailymotion are popular platforms for accessing content, and recently many Pakistani producers have started producing web series which can be accessed through digital media only. Surprisingly, $10 \%$ of the 340 million monthly visits to dailymotion.com are from Pakistani viewers, which makes the video content website, Dailymotion, among the top five most popular websites in Pakistan (Rammal, 2015).

In print media, according to the Pakistan Bureau of Statistics, 707 newspapers are currently operating in Pakistan, as of the year 2019 (Statistics, 2019). Newspapers have a specialization in traditional political news coverage, and are also considered more credible by the advertisers. All leading newspapers in Pakistan also have online subscriptions and provide easy access via the internet. Globally, newspapers have largely gone from analog to digital (Hultin \& Skog, 2011), e-Papers are cheaper 
and most advertisers are now interested in online media platforms (Kalombe \& Phiri, 2019). In addition to this, different niches within the news domain have been occupied by nascent and traditional media (J. Dimmick et al., 2011). In this regard, there is evidence of the displacement of print media by the internet (Cowen, 2001; Haniff, 2012; Nguyen \& Western, 2006; Yi \& Sung, 2007). The introduction of online editions, use of paywall, free online views, search engine optimization, and micro-funding are some common strategies that have been opted by the print media of the USA industry against any recessionary periods (Ekeanyanwu et al., 2017).

\subsection{Data Collection and Analyses}

Comparative media studies have been observed to be fruitful in analyzing the external factors affecting media economics (Chan-Olmsted, 2004). According to Dimmick (2013), using market share reports as secondary data is the only available and viable source for analyzing the competition for advertising resources among media forms. Market analysis is dependent on the available data, and is performed at various levels (Barrett, 1996). It has to be noted that unfortunately, there is a scarcity of data in Pakistan related to advertising media market reports. The sample for the current study comprises all the available annual advertising spend reports of the media forms in Pakistan available online, as provided by Gallup Pakistan and Aurora by Dawn group (which is a leading advertisng, marketing and media magazine), focused on the market share of the media industry annually. The advertising spend reports that were available online, from the year 2000-2019 constitute the population of this study. In order to confirm the validity and reliability of the online data, Aurora was requested to share the official record of these reports, which was received via email. Furthermore, the data for 17 years, extracted from the years pertaining to 2000-2019 were sampled out for the overall trend analysis, as the data from the years 2002-2004 was missing. A complete breakdown of the individual media market shares for 17 years was not available. therefore, the advertising market spends of individual media forms for 12 years i.e. 2007-2019 was gathered from the online reports by Gallup (Media cyber letter), and Aurora (Media advertising spend reports). These media market share reports of Aurora and Gallup are available online and are accessible to internet users. The data included media including radio, TV, print, digital, out of home $(\mathrm{OOH})$ and brand activation POP (Point of purchase). Out of home $(\mathrm{OOH})$ and brand activation POP (Point of purchase) were excluded from the data, as they had a different nature of message production, and do not purvey content like radio, TV and print and digital media, as guided by Dimmick (2002). 
The digital media started gathering its share from the advertising market in Pakistan, and its market share was reported in the annual advertising reports that were published in the year 2011. Therefore, the advertising market share sample was restricted to 8 years for comparison with the other media forms for which the data was collected from the years spanning from 2011-2019.

According to Dimmick (2002), the advertising spending subdivisions or micro dimensions are represented by categories such as spot, local and national or network for TV and radio or national, local and classified for newspapers, while for the Internet there is as yet a single dimension. Since the data specific to advertising spending in the micro dimensions of TV, radio and print is not available in Pakistan, therefore, due to lack of micro dimensions data for advertising spending, this analysis has proceeded in the following manner, using various statistical methods following the studies (Dimmick, 2013; Yousuf, 2016). For the purpose of this study, the statistical analyses comprise of four methods. The first form of data analysis highlight is the trends of total advertising spend and media market share of individual media organizations, which has been analyzed and presented as the graphic representation in this study. The second type of data analysis presents the comparison of average market shares of various media forms/types using the ANOVA, in order to understand the difference in advertising market shares. Also, Tukey's post hoc analysis has been employed to understand the pairwise difference between the average spending on different mediums. The third form analyzes the relationship between traditional (old) media forms (TV, radio and print), with the new media (digital media), by using Kendall's tau$\mathrm{b} /$ correlation analysis. This analysis also specifically investigates the relationship between the advertising market share of radio and other media forms including TV, print and digital media. The last type focuses on the relationship between the independent variable (media type) and the dependent variable (media expenditure), primarily by using the regression analysis to explore the relationship between media expenditure and media type. It is noteworthy that the purpose of applying multiple statistical methods is to analyze the competition or displacement of media forms from a variety of dimensions. Lastly, the statistical analysis was carried out by making use of the SPSS 25.0 software. 


\section{Data Analysis and Results}

\subsection{Advertising Spending Trends in the Media Market}

According to Figure 1, the overall share of advertising spending shows that the total advertising expenditure for media continues to grow, but the data from the FY 2017-18 and FY 2018-19 show that the advertising budget of media remains constant in these two points of time. The maximum share of the advertising spend on media reached a staggering 87.7 billion in FY2016-17, with a maximum percentage increase of $31 \%$ for two consecutive years pertaining to FY 2005-07, as shown in Figure 2. Then, a sudden decline is observed in FY 2017-18, and this declining trend is observed to continue in the next FY 2018-19. Moreover, the globalization index has a significant correlation with the percentage of media expenditures in GDP (Zhang \& Albarran, 2018). Pakistan's latest available overall Globalization index in 2017 was 56.11, as compared to the world average i.e. 64.15 , and this is expected to grow slower in the future as well (SwissEconomicInstitute, 2017). Several other factors influence the total advertising spend of media in Pakistan, including the revised Government policies for media advertising quota, lower pricing of government advertisements, and unstable political and economic conditions.

Figure 1. Total Media Expenditure Trend

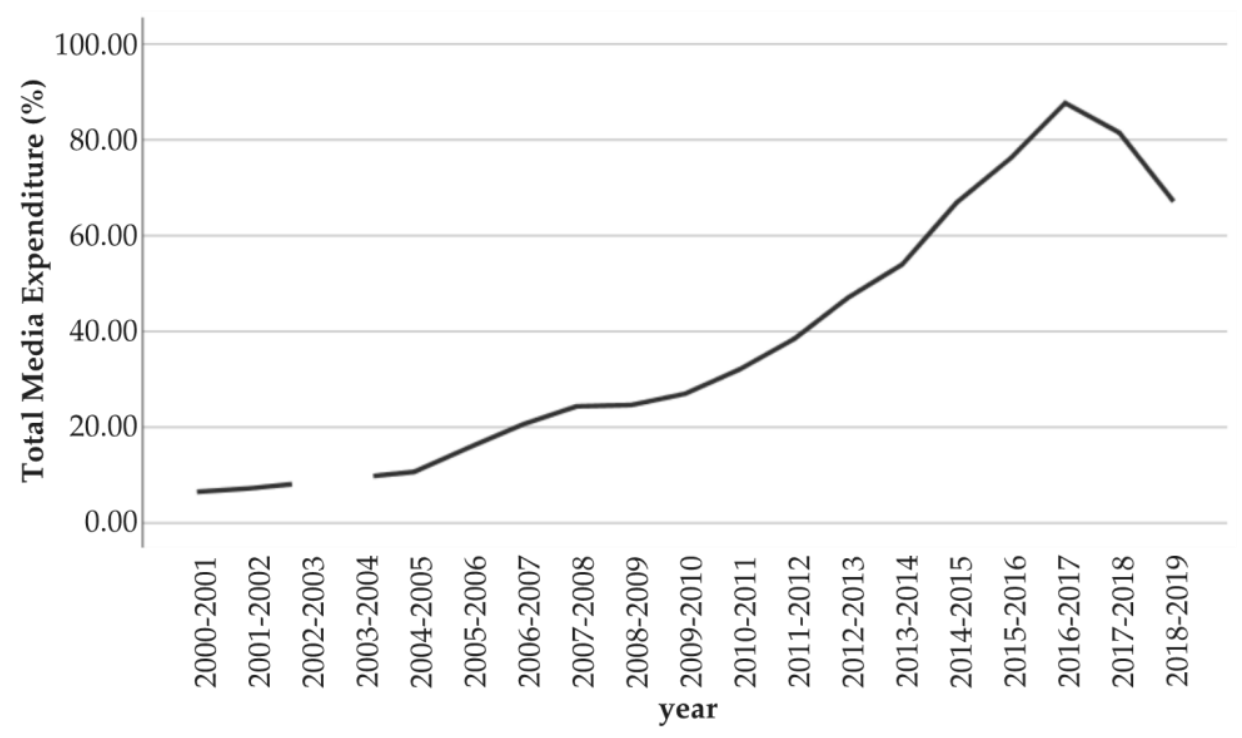




\section{Figure 2. Total Advertising Market Spend}

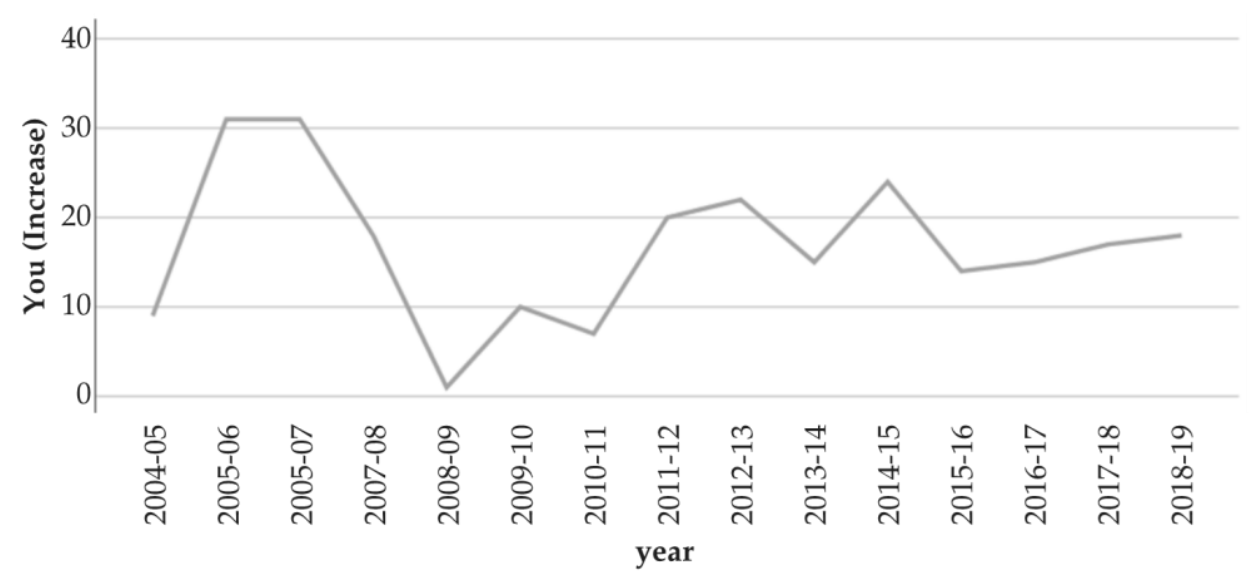

Figure 3. Trends of Media Expenditure for each Media Type

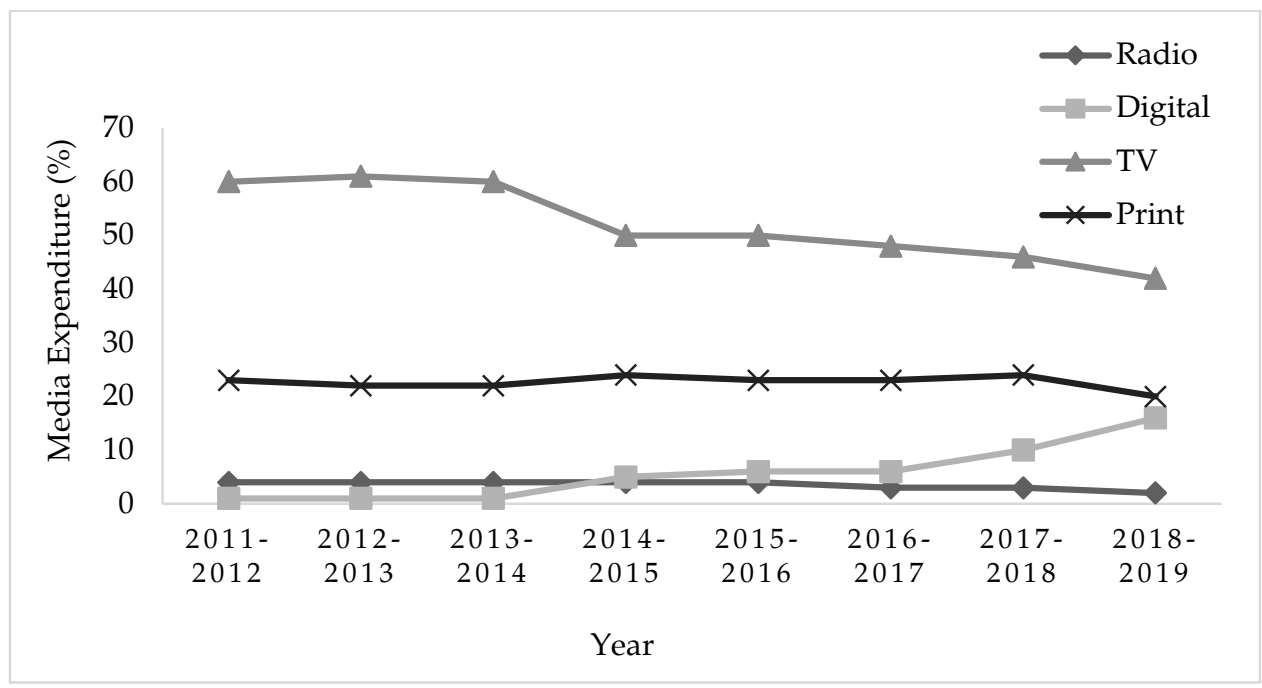

Figure 3 shows the trend in media spending with the help of a line graph from FY 2011-19 for different mediums of media. The reason for restricting the analysis to 2011-19 is primarily that the share of digital media had been reported in Pakistan's media market for the first time in the year 2011. Advertising expenditure on the radio had not shown any trend until FY 2016-17. Rather, it showed a constant pattern of spending in terms of time. A slight decline had been observed in the last two periods. Also, a sudden downfall has been observed in the market shares of TV for FY 201415. However, after that period, the pace of decline seemed to have slowed down. The traditional media (TV, radio, print) market share in advertising 
showed a downfall in the year 2019. Digital media held a small share in the market, though it showed a gradually increasing trend after FY 2013-14 in the market share. Moreover, it is the only media showing a steadfast yearon-year increase. It is evident from Figure 3 that TV still holds a substantial chunk of market share, primarily because it is a generalist medium. The medium of radio is now moving critically downward in terms of its market share, and stood at a share level of only $2 \%$ in the year 2019. The decrease in the print media market share also denotes that digital media will soon cross its market share in the coming years.

\subsection{Differences between Traditional and New Media Advertising Shares in the Media Market}

This section of the study analyzes the variation in the average market shares of various media forms/types, using the Analysis of Variance (ANOVA) technique. The results for the ANOVA technique indicated that the mean spending on different media groups is statistically significantly different $(p$-value $=0.000)$ from each other.

Table 1: Analysis of Variance among Advertising Shares

\begin{tabular}{lccccc}
\hline \multicolumn{7}{c}{ Expenditure } \\
\hline & Sum of Squares & df & Mean Square & F & Sig. \\
\hline Between Groups & 17505.909 & 3 & 5835.303 & 228.388 & .000 \\
Within Groups & 1022.000 & 40 & 25.550 & & \\
Total & 18527.909 & 43 & & & \\
\hline
\end{tabular}

As shown in the Table- 1, the ANOVA indicates that the groups are statistically significantly different (F228.388; p-value $=0.000)$, based on the advertising expenditure. Moreover, Tukey's test has been applied for further investigation of the pairwise difference between the average spending on different mediums.

\section{Table 2: Tukey's HSD Comparisons among Media Advertising Expenditure}

\begin{tabular}{lccccccc}
\hline & & & & \multicolumn{4}{c}{ Tukey's HSD Comparisons } \\
\cline { 6 - 8 } Group & $\boldsymbol{n}$ & Mean & SD & Print & Radio & Digital & TV \\
\hline Print & 12 & 24.33 & 5.365 & & .000 & .000 & .000 \\
Radio & 12 & 3.42 & .996 & .000 & & .744 & .000 \\
Digital & 8 & 5.75 & 5.230 & .000 & .744 & & .000 \\
TV & 12 & 52.58 & 6.762 & .000 & .000 & .000 & \\
\hline
\end{tabular}


The table above shows some of the important descriptive values and confidence intervals for the mean values of the advertising market spend for each medium. The maximum chunk $(52.58 \pm 6.762)$ of advertisement expenditure has been grasped by TV, followed by print media $(24.33 \pm 5.365)$. Moreover, the average spending on both Radio (3.42 \pm 0.996$)$ and digital media $(5.75 \pm 5.230)$ is substantially lower, as compared to TV and print media. Another noticeable finding has been that the variability can be observed in digital media spending over a span of eight years. As the variation in the yearly spending for digital media has experienced an increasing trend, it means this new medium is emerging rapidly. Furthermore, the results of Tukey's Post Hoc test revealed that the spending on advertisement by Radio is significantly different ( $p$-value $=0.000<0.05)$ from TV and Print Media. However, there is no significant difference ( $\mathrm{p}-$ value $=0.744>0.05$ ) between the expenditure on Radio and Digital Media. The advertising expenditure of radio has been surpassed by that on digital media, as it is deemed to be more effective. The overlapping between their expenditures points out towards the competition for advertising expenditure between radio and digital media, which can result in the displacement of one medium which is a specialist i.e. radio. The results are also supported by the trend analysis, which shows a continuous downward trend in advertising spending on radio as a medium.

\subsection{Relationship between Traditional and New Media Advertising Shares in the Media Market}

Certain directional relationships have been tested following the founding objectives of the study and literature review (Churchill \& Iacobucci, 2006; Ruxton \& Neuhäuser, 2010; Zar, 1999). In this study, it has been assumed from the secondary data observation that the effects (increase or decrease) experienced in the advertising market share of traditional media have been brought in due to the advent of the digital media market, in the advertising media market of Pakistan. Thus, the relationship testing has been generated in order to check the strength and direction of the relationship among the variables, after observing the general trends as shown in Figure 3. The results of the ANOVA test have suggested a significant level of variability in the advertising market shares of the media forms, and overlapping between the advertising market shares of the radio and digital media. However, the influence of the digital media market shares on the other traditional media forms i.e. TV and print, require a correlation analysis, with a particular reference to, and focus on digital media. Kendall's Tau-B has been used to analyze the relationship. 


\section{Table 3: Correlations Between Variables of Study (Digital versus Traditional media)}

\begin{tabular}{lccccc}
\hline & & Radio & Digital & TV & Print \\
\hline Kendall'sDigital & Correlation Coefficient & $-.792^{* *}$ & 1.000 & $-.921^{* *}$ & .128 \\
tau_b & Sig. (1-tailed) & .008 &. & .001 & .344 \\
& $\mathrm{~N}$ & 8 & 8 & 8 & 8 \\
\hline
\end{tabular}

**. Correlation is significant at the 0.01 level (1-tailed).

* Correlation is significant at the 0.05 level.

It can be observed from Table 3 that a significantly inverse relationship exists between the advertisement spending on digital media $\&$ TV (tau- $\mathrm{b}=-0.921 ; \mathrm{p}$ value $=0.001)$, and digital media and Radio (tau- $\mathrm{b}=-$ 0.792; $\mathrm{p}$ value $=0.008$ ) platforms. On the contrary, a significant positive relationship has been found between digital media and print media (tau$b=0.128 ; p$ value $=0.344$ ). However, the correlation coefficient shows a weak relationship that has a value that is near to zero, thus indicating that there exists no strong correlation among the variables. The advertising market share of digital media and radio is found to be significantly negative $(r=-0.792, p$ value $=0.008)$ and associated with each other at a $5 \%$ level of significance. The value of Kendall's Tau-B has also suggested a strong (negative) linear relationship. An increase in the market share of digital media expenditure has resulted in a significant decline in the market share of radio advertisements. A further stronger negative association has been observed between the advertising market share of TV and digital media. The increase in the market share of digital media has significantly declined $(\mathrm{r}=-0.921, \mathrm{p}$ value $=0.001)$ the market share of TV advertisements. The correlation value between TV and digital media has given the most significant results, denoting that an even stronger competition exists between TV and digital media in the advertising resource dimension, as compared to radio. However, TV maintains a lion's share in the advertising domain, primarily because of it being a generalist medium. Moreover, the relationship between the market share of digital media and print media has been significantly positive $(r=.128, p$ value $=0.344$ ). However, the value of Kendall's Tau-B correlation coefficient has indicated a weak positive relationship between both the considered variables. It can thus be interpreted that print media has experienced a cut in advertising market share, mainly due to the widespread advent of digital media. It is evident that print media will be surpassed by digital media advertising share in a few years, as the trend has (Figure 3 ) indicated 
a downfall which first started in the year 2019 in the advertising market share of print media.

\subsection{Relationship between Media expenditure and Media type.}

The fourth step of analyses tests the relationship between advertising media expenditure and media types, using the simple regression analysis. The summary results of the goodness of fit test have provided evidence that the data is a good fit for the simple linear regression model, with a highly significant $\mathrm{p}$-value (0.000)

Table 4: Relationship between Advertising Media Expenditure and Media Type

\begin{tabular}{|c|c|c|c|c|c|c|c|c|}
\hline \multirow[t]{2}{*}{ Model } & \multirow{2}{*}{$\mathbf{R}$} & \multirow{2}{*}{$\begin{array}{c}\mathbf{R} \\
\text { Square }\end{array}$} & \multirow{2}{*}{$\begin{array}{l}\text { Adjusted } \\
\text { R Square }\end{array}$} & \multirow{2}{*}{$\begin{array}{l}\text { Std. Error } \\
\text { of the } \\
\text { Estimate }\end{array}$} & \multicolumn{4}{|c|}{ Change Statistics } \\
\hline & & & & & $\begin{array}{l}\text { R Square } \\
\text { Change }\end{array}$ & $\begin{array}{c}\text { F } \\
\text { Change df1 }\end{array}$ & df2 & $\begin{array}{l}\text { Sig. F } \\
\text { Change }\end{array}$ \\
\hline 1 & $.977^{a}$ & .954 & .950 & 4.537 & .954 & 195.6843 & 28 & .000 \\
\hline
\end{tabular}

Table 5: Analysis of Variance

\begin{tabular}{lccccc}
\hline Model & Sum of Squares & df & Mean Square & F & Sig. \\
\hline 1 Regression & 12081.750 & 3 & 4027.250 & 195.684 & $.000^{\mathrm{b}}$ \\
Residual & 576.250 & 28 & 20.580 & & \\
Total & 12658.000 & 31 & & & \\
\hline
\end{tabular}

a. Dependent Variable: Media Expenditure

b. Predictors: (Constant), Radio1, Print1, TV1

Table 6: Influence of Digital Media on Traditional Media Market Shares

\begin{tabular}{|c|c|c|c|c|c|c|c|c|}
\hline \multicolumn{9}{|c|}{ Coefficients } \\
\hline & & \multicolumn{3}{|c|}{$\begin{array}{cc}\text { Unstandardized } & \text { Standardized } \\
\text { Coefficients } & \text { Coefficients }\end{array}$} & \multirow[b]{2}{*}{$\mathbf{t}$} & \multirow[b]{2}{*}{ Sig. } & \multicolumn{2}{|c|}{$\begin{array}{l}95.0 \% \text { Confidence } \\
\text { Interval for B }\end{array}$} \\
\hline \multicolumn{2}{|c|}{ Model } & B & $\begin{array}{l}\text { Std. } \\
\text { Error }\end{array}$ & Beta & & & $\begin{array}{l}\text { Lower } \\
\text { Bound }\end{array}$ & $\begin{array}{l}\text { Upper } \\
\text { Bound }\end{array}$ \\
\hline \multirow[t]{4}{*}{1} & (Constant) & 5.750 & 1.604 & & 3.585 & .001 & 2.465 & 9.035 \\
\hline & TV1 & 46.375 & 2.268 & 1.010 & 20.445 & .000 & 41.729 & 51.021 \\
\hline & Print1 & 16.875 & 2.268 & .367 & 7.440 & .000 & 12.229 & 21.521 \\
\hline & Radio1 & -2.250 & 2.268 & -.049 & -.992 & .330 & -6.896 & 2.396 \\
\hline
\end{tabular}

a. Dependent Variable: Media Expenditure 
It is evident that from Table 4 that a $95.4 \%$ ( $\mathrm{R}$ square $=0.954$ ) variability in the media expenditure has been accorded by the type of media that has been taken into consideration. The overall significance of the model has been reported in Table 5 ( $F=195.684$, p-value $<=0.000)$. It can be observed that the expenditure on TV is 46.375 times more, as compared to digital media (Table 6). In addition to this, the expenditure made on print media is calculated to be 16.875 times more as compared to digital media. Also, the expenditure on radio indicates that there is -2.250 times less advertising spending on radio, as compared to digital media. However, it is not significant.

The results have been reported as per the previous results of ANOVA and the correlation analysis. It can be observed that TV still holds a good position in the advertising market, primarily because it is a generalist medium. However, the effects of digital media on TV have been indicative of strong competition between these two media. Also, print media has been losing its market share gradually. This is mainly due to the advent of digital media, and the difference in their market shares which is eventually going to decrease within a few more years. Radio being a smaller and vulnerable media industry has also been severely affected by the advent of digital media in the advertising market. However though, the degradation is slow, but if the negative trend continues, traditional radio can potentially be on the verge of displacement in terms of its advertising market share.

\section{Discussion}

According to Dimmick's (2002) theory of the niche, it is deemed that a generalist medium is better equipped to withstand the competitive environment in the industry. That is to say that, TV being a generalist medium, might be displaced on one dimension by a nascent medium, but there might be an absence of competition on the other resource dimensions. According to the life cycle of new media, the second stage is growth (16\%$50 \%$ ), as quoted in section 2.2 (Lehman-Wilzig \& Cohen-Avigdor, 2004), nascent media in Pakistan has entered the second stage. It is believed that during this time, it has captured $16 \%$ of the advertising market, and the developers and users have rapidly started using the nascent media. Moreover, It is also believed to be in a stage of institutionalization, as discussed in section 2.2 (Caspi, 1993). The most vulnerable among the traditional media is the radio industry, which appears to be on the verge of 'mediacide', as explained in section 2.2 (O'Brien, 1999). In order for the specialist industries (radio and print) to survive, they need to develop and 
build the niches that are specific to them, and are meant for an audience of particular interest (Dimmick, 2002).

In comparison to the previous studies conducted in this area of advertisement spending between traditional and nascent media, there are similarities and differences in the results observed in the current study. Keeping in view the previous two studies, it was observed that TV appeared as a nascent media. Moreover, a high overlap was revealed with radio and newspaper in terms of their advertising spending, and the nascent media for the current study i.e. digital media depicts similar patterns in the case of radio (Dimmick \& Rothenbuhler, 1984). An identical pattern of high overlap, which was previously observed between TV and nascent media (cable), has also been observed in the current study. This time though, it was between the advertising market share of the radio and the nascent medium i.e. digital media. However, the assertion that 'radio remains competitive' appears inconsistent with the current findings (Dimmick et al., 1992). The results of the current study, conducted in the parameters of the Pakistani context, unravel the competition of traditional media with nascent media, and the results, thereof, are consistent with the previously conducted study in the US (Dimmick et al., 2004). The trend and correlation analysis also support the long-term displacement of newspaper advertising, as previously observed (Dimmick, 2013). The downfall in print media advertising share in the year 2019 has threatened its stability of holding low market shares for the past many years in the advertising media market. In this regard, it can be assumed that print media will continue to lose its advertising market share to digital media in the coming years. Also, TV stands with the major market share as a generalist medium, however, the downfall in its market share accounts for the competition of TV and digital media for advertising market share, which is also evident from the statistical analyses.

Multiple statistical analyses have addressed all the objectives that have been undertaken in this study. The statistical analyses have collectively concluded that traditional media is now experiencing a downfall in the advertising media market, primarily due to digital media. The first objective of the study measured the variability among the advertising market share of media forms, using the ANOVA test which identified a niche differentiation among the advertising spend of various media forms. then, the correlation and regression analysis addressed the second objective of the study, and are similar to measuring the niche breadth and competitive superiority of a medium, thus indicating that the generalist medium has maintained its dominance in advertising share in 
the advertising media market, and has a lesser influence of nascent media. A statistically significant negative association between the advertising share of the two mediums would therefore appear to be an indication of displacement on the advertising micro dimension (Dimmick, 2002). Moving on, Kendall Tau's correlation test indicates an inverse advertising market share of radio to digital media. The results of the regression analysis achieved the third objective of the study, and also accounted for a negative share of radio, as compared to digital media. The fourth objective of the study has been achieved by identifying the similarity in advertising expenditure of digital media and radio, using Tukey's Post Hoc, which is similar to measuring the overlap in the area of advertising market share of both the media forms, and indicates no statistically significant difference among their market shares. According to the media niche theory, the higher the overlapping, the higher will be the competition. The results of the competition are further supported by a trend analysis, where radio as a media shows a flat advertising budget, until the year 2016, followed by a fall in the advertising budget percentage. Though this fall is $1 \%$ of the total advertising expenditure, however, it translates into a fall of $25 \%$ in the radio advertising stream (from $4 \%$ to $3 \%$ ), which is considered a big blow for a specialist media industry such as traditional radio, which shares a small piece of cake, and its share does not come as a surprise. Radio is now moving critically downward in terms of its market share, and stood at a mere $2 \%$ for the year 2019. Based on these analyses related to traditional radio advertising market share, it can be concluded that radio as a media has a shrinking advertising budget every year, primarily due to the nascent media form. It can be asserted that the biggest blow to the market share has been faced by the radio industry.

\section{Conclusions}

This study has made a significant contribution to the field of media management and economics in Pakistan. It is common knowledge that revenue is the core of the media business that comes through advertisements. In this regard, there had only been speculations and raw data related to the advertising market share of digital media, based on the internet and its relationship with traditional media business in Pakistan. This study has aimed to fill in this gap by contributing to the scarcity of research in this area, as it has comprehensively examined the total advertising spend and individual media market share by media forms i.e. $\mathrm{TV}$, radio, print and digital, using various statistical analyses. The current state of the advertising spend in Pakistani media has been termed as the 'dark days'. An important reason for this could be the economic recession 
which is forcing companies to reduce the budgets that are allocated for media advertisements (Shaikh, 2019). From the data, it appears that in the beginning, the increase in the digital advertisement was mainly cutting into the share of the dominant media i.e. TV. However, it has been observed that in terms of radio as a medium, there is an alarming downward trend since the last couple of years due to the widespread use of digital media, which has significantly eroded the already small share of traditional radio. This implies that digital media has also taken up the local advertisements on a significant scale, thus taking away the already small share of radio advertisement, with a significant reduction in the overall market spend. This raises a huge red flag for the continued profitable operations of radio platforms. It is also to be noted that $\mathrm{OOH}$ (Out of Home) media and brand activation, are not taken into consideration as part of this analysis. This is primarily because they are considered as means of advertisements only, and do not purvey content in the way that TV, print and radio do. It is also noteworthy that these media platforms have also developed significantly over the past few years, and held approximately $19 \%$ of the total advertising share, as of the year 2018-19.

Digital media will continue to grow its advertising market share by indulging in further diversification, global operations and exploitation of economies of scale for traditional media. It is important to discuss whether the resource dimension of advertising spends on media is adding new money for the nascent industry, or the digital industry is serving as a substitute for the traditional media. According to the data extracted, it represents a sudden fall in the total advertising spend i.e. 87.7 billion (201617) to 81.5 billion (2017-18), and then 67.15 billion (2018-19). This indicates that the overall resource dimension of the advertising spend in Pakistan for the media market is shrinking. According to the Media Niche Theory, if there is no significant increase in the total advertising spending every year, the entrance of a new competitor i.e. digital media may lead to tough competition. The impact of the COVID-19, which is a true "black swan" event, has created an upheaval in the media industry, the effects of which cannot be predicted at this point, and will need a few years for us to understand. Some of these changes will permanently affect the future of the industry, while the rest will be transitory i.e. reverting to the previous stage over time.

\section{Recommendations and Implications}

The study holds an important position in the field of, mass media industry analysis and management. This is because it clearly defines the 
position and influence of digital media, on various media organizations, in the domain of advertising market share in the media ecosystem of Pakistan. In addition to this, the study suggests several guidelines for the policymakers, media owners, content producers and researchers of the traditional media industry, in order to ensure positive business outcomes.

Firstly, the availability of extensive data in the adverting industry is a prerequisite for future analyses, and for ascertaining the way forward. Therefore, all the stakeholders should fund and organize an initiative for the collection, collation and analysis of detailed data, which should emphasize the different micro dimensions (spot, local, national, classified) related to the advertising revenue of different media. Secondly, specialist industries need to acquire a different competitive strategy which can result in niche differentiation, which might include a price difference for advertisements. Moreover, Radio as a media platform, should enhance its presence through websites, social media posts, podcasts and blogs using modern programming techniques, so as to collect its share from the digital dimension, thereby improving the business. Thirdly, the radio business in Pakistan is on the verge of displacement, and in order to save the industry from its ultimate downfall, drastic steps and efficient strategies are needed by the radio professionals. The major failure of radio in Pakistan is its inability to capture the digital market, its slow-paced shift towards innovation, and a lack of diversity in the content, which has resulted in a substantial decline of its market share. In addition to this, in the future researchers can replicate the research design of the current study, in order to gain insight into the respective media market belonging to different geographical areas. The effects and relationship among media industries in the business market need to be studied, as the results might differ from those obtained in technologically advanced countries, as has been observed in the current study. This can help in developing a policy of media business and economics for the media industry.

\section{Research Limitations and Future Research Directions}

The current research is a pioneering effort in analyzing the advertising media market in Pakistan and the effect of the nascent medium, i.e. digital media, on the advertising market of traditional media forms. The main constraint that was faced by the researcher was the paucity of data, which impeded the calculations of the niche metrics due to the absence of micro dimensions in the advertising data. 
An area for future research would be to record data for micro dimensions of advertising market share which includes calculating advertising market share expenditure of media forms in the subdivisions of local, spot, classified and national. A detailed examination of advertising spending on digital media can be conducted in the future which may include studying various digital platforms i.e. Facebook, Twitter, YouTube, etc. and their significance in the advertising media market as alternatives to traditional media forms. Researchers can conduct media market analyses in the future by integrating theories of media, management and economics to predict the business and positioning of various media forms in the media ecosystem. 


\section{References}

Abbas, J., Aman, J., Nurunnabi, M., \& Bano, S. (2019). The impact of social media on learning behavior for sustainable education: Evidence of students from selected universities in Pakistan. Sustainability, 11(6), 1683.

Adoni, H., \& Nossek, H. (2001). The new media consumers: Media convergence and the displacement effect. Communications-Sankt Augustin then Berlin-, 26(1), 59-84.

Albarran, A. B. (1996). Media economics: Understanding markets, industries and concepts: Iowa State University Press Ames.

Albarran, A. B. (2006). Historical trends and patterns in media management research. Handbook of media management and economics (pp. 16-34): Routledge.

Albarran, A. B., Anderson, T., Bejar, L. G., Bussart, A. L., Daggett, E., Gibson, S., ... Horst, J. L. (2007). "What happened to our audience?" Radio and new technology uses and gratifications among young adult users. Journal of Radio Studies, 14(2), 92-101.

Albarran, A. B., \& Dimmick, J. W. (1993). An assessment of utility and competitive superiority in the video entertainment industries. Journal of Media Economics, 6(2), 45-51.

Aurora. (2019, 13/2/2019). Media Advertising Spend FY 2017-18, 2019. https://aurora.dawn.com/news/1143364

Barrett, C. B. (1996). Market analysis methods: are our enriched toolkits well suited to enlivened markets? American Journal of Agricultural Economics, 78(3), 825-829.

BBC. (2019, 20/12). بى بى سى اردو: سبربين كى ريذيو نشريات بند بو ربى بـ BBC https://www.bbc.com/urdu/pakistan-50874269

Cancian, M., Bills, A., \& Bergstrom, T. (1995). Hotelling location problems with directional constraints: an application to television news scheduling. The Journal of Industrial Economics, 43(1), 121-124. 
Carroll, G. R. (1985). Concentration and specialization: Dynamics of niche width in populations of organizations. American Journal of Sociology, 90(6), 1262-1283.

Caspi, D. (1993). Mass Communications (vol. 1, in Hebrew). Ramat-Aviv, Israel: Open University.

Caves, R. E. (2000). Creative industries: Contracts Between Art and Commerce: Harvard University Press.

Chan-Olmsted, S. M. (2004). Introduction: Traditional media and the internet: The search for viable business models. International Journal on Media Management, 6(1-2), 2-3.

Churchill, G. A., \& Iacobucci, D. (2006). Marketing Research: Methodological Foundations: Dryden Press New York.

Cowen, N. (2001). The future of the British broadsheet newspaper on the World Wide Web. Paper presented at the Aslib Proceedings: New information perspectives.

Dimmick, \& Rothenbuhler, E. (1984). The Theory of the Niche: Quantifying Competition Among Media Industries. Journal of Communication, 34(1), 103-119. https:/ / doi.org/10.1111/j.1460-2466.1984.tb02988.x

Dimmick, J. (2013, August). Diffuse Competition and the Decline in US Newspaper Advertising [Paper presentation]. Media Management and Economics Division of the Association for Education in Journalism, Washington, DC.

Dimmick, J., Chen, Y., \& Li, Z. (2004). Competition between the Internet and traditional news media: The gratification-opportunities niche dimension. The Journal of Media Economics, 17(1), 19-33.

Dimmick, J., Feaster, J. C., \& Hoplamazian, G. J. (2011). News in the interstices: The niches of mobile media in space and time. New Media E Society, 13(1), 23-39.

Dimmick, J., \& McDonald, D. G. (2001). Network radio oligopoly, 19261956: Rivalrous imitation and program diversity. The Journal of Media Economics, 14(4), 197-212. 
Dimmick, J., \& Rothenbuhler, E. (1984). Competitive displacement in the communication industries: New media in old environments. The New Media, 287-304.

Dimmick, J. W. (2002). Media competition and coexistence: The theory of the niche: Routledge.

Dimmick, J. W., Patterson, S. J., \& Albarran, A. B. (1992). Competition between the cable and broadcast industries: A niche analysis. Journal of Media Economics, 5(1), 13-30.

Dimmick, W., \& McDonald, D. (2000, May). Time as a niche dimension: competition between the Internet and television [Paper presentation]. International Media Economics Conference: Time and Media Markets, University of Navarra, Pamplona, Spain.

Ekeanyanwu, N. T., Batta, H., \& Oyokunyl, J. I. (2017). The Economics of Decline in the Media Industry: Survival Strategies of American Print Media Firms and Implications for a Diminishing Print Media Industry in Nigeria. Journalism, 7(8), 427-445.

Ferguson, D. A., Greer, C. F., \& Reardon, M. E. (2007). Uses and gratifications of MP3 players by college students: Are iPods more popular than radio? Journal of Radio Studies, 14(2), 102-121.

Gabszewicz, J. J., Laussel, D., \& Sonnac, N. (2006). Competition in the media and advertising markets. The Manchester School, 74(1), 1-22.

Gallup. (2017). Pakistan Media Report; National Media Habits.

GroupM. (2018). 3D Radio Insights.

Haniff, Z. (2012). Niche Theory in new media: Is digital overtaking the Print Magazine Industry? [Master's thesis, University of Nevada]. UNLV. https://digitalscholarship.unlv.edu/thesesdissertations/1571/

Hellman, H., \& Soramäki, M. (1994). Competition and content in the US video market. Journal of Media Economics, 7(1), 29-49.

Hoplamazian, G. J., Dimmick, J., Ramirez Jr, A., \& Feaster, J. (2018). Capturing mobility: The time-space diary as a method for assessing media use niches. Mobile Media E Communication, 6(1), 127-145. 
Hultin, J., \& Skog, D. (2011). The digitalized newspaper organization: An identity crisis in the midst of the challenges of being early adopters of converged digital services [Bachelor's thesis, Umeå University, Faculty of Social Sciences, Sweden]. DiVA. https://www.divaportal.org $/ \mathrm{smash} /$ record.jsf?dswid=-6781\&pid=diva2 $\% 3 \mathrm{~A} 425990$

Kalombe, C., \& Phiri, J. (2019). Impact of Online Media on Print Media in Developing Countries. Open Journal of Business and Management, 7(04), 1983.

Kemp, S. (2020). Digital 2020: Pakistan.

Lebni, J. Y., Toghroli, R., Abbas, J., NeJhaddadgar, N., Salahshoor, M. R., Mansourian, M., ... Azizi, S. A. (2020). A study of internet addiction and its effects on mental health: A study based on Iranian University Students. Journal of Education and Health Promotion, 9(1), 205, https://doi.org/10.4103/jehp.jehp_148_20

Lehman-Wilzig, S., \& Cohen-Avigdor, N. (2004). The natural life cycle of new media evolution: Inter-media struggle for survival in the internet age. New Media \& Society, 6(6), 707-730.

McChesney, R. W. (2008). The political economy of media: Enduring issues, emerging dilemmas: New York Univeristy Press.

McFadden, J. B. (2010). Understanding media and culture: An introduction to mass communication. Minneapolis: University of Minnesota Libraries.

McPhillips, S., \& Merlo, O. (2008). Media convergence and the evolving media business model: An overview and strategic opportunities. The Marketing Review, 8(3), 237-253.

Napoli, P. M. (1998). The Internet and the forces of "massification". Electronic Journal of Communication, 8(2).

Nawaz, S. (1983). The mass media and development in Pakistan. Asian Survey, 23(8), 934-957.

Nelson, R. R., \& Winter, S. G. (1982). The Schumpeterian tradeoff revisited. The American Economic Review, 72(1), 114-132.

Nguyen, A., \& Western, M. (2006). The Complementary Relationship between the Internet and Traditional Mass Media: The Case of 
Online News and Information. Information Research: An International Electronic Journal, 11(3), n3.

Nielsen, J. (1998). The end of legacy media (newspapers, magazines, books, TV networks). NN/g Nielsen Norman Group.

O'Brien, M. (1999). Newspapers on the Internet-with a case study of the Nando Time. research paper, Junior MagZINE Journalism, University of Texas, Austin, URL (consulted January 2001): http://uts. cc. utexas. edu/ maggs/paper. html.

PEMRA. (2021). FM Radio Retrieved 10/18, 2021, from https://pemra.gov.pk/fm.php

Rammal, A. (2015). How digital is affecting ad spend. Aurora.

Redmond, J. W. (2006). Issues in human relations management. In A. B. Albarran, S. M. Chan-Olmsted \& M. O. Wirth (Eds.), Handbook of media management and economics (1 ${ }^{\text {st }}$ ed., pp. 125-154). New Jersey: Routledge.

Ries, A., \& Ries, L. (2000). The 11 immutable laws of internet branding. Harper Collins Publishers.

Rogers, E. M. (1986). Communication: The new media in society. New York: The Free.

Rosenkrans, G. (2009). The creativeness and effectiveness of online interactive rich media advertising. Journal of Interactive Advertising, $9(2), 18-31$.

Ruxton, G. D., \& Neuhäuser, M. (2010). When should we use one-tailed hypothesis testing? Methods in Ecology and Evolution, 1(2), 114-117.

Saffo, P. (1992). Paul Saffo and the 30-year rule. Design world, 24(1), 16-23.

Shaikh, A. (2019). Facing up to performance in 2020. Dawn. https://aurora.dawn.com/news/1143615/facing-up-toperformance-in-2020

Statistics, P.B.o. (2019). Newspapers \& Periodicals by Province. http://www.pbs.gov.pk/content/newspapers-periodicalsprovince 
Steiner, P. O. (1952). Program patterns and preferences, and the workability of competition in radio broadcasting. The Quarterly Journal of Economics, 66(2), 194-223.

Stöber, R. (2004). What media evolution is: A theoretical approach to the history of new media. European Journal of Communication, 19(4), 483505.

SwissEconomicInstitute, K. (2017). KOF Globalisation Index. KOF Swiss Economic Institute.

Tahir, S. N. (2002). Community Radio a Tool of Social Change: Still a Far Cry in Pakistan. University of Punjab, 19.

Townley, B., Beech, N., \& McKinlay, A. (2009). Managing in the creative industries: Managing the motley crew. Human Relations, 62(7), 939962.

Wen-jing, H. (2014). Incentive of Participation: Audience Behavior Management of Digital Media Advertising Communication. Journal of Advertising Study, 4, 41 .

Wicks, J. L., Sylvie, G., \& Hollifield, C. A. (2004). Media management: A casebook Approach: Routledge.

Yi, K., \& Sung, Y. (2007). What to read in the morning? A niche analysis of free daily papers and paid papers in Korea. The International Journal on Media Management, 9(4), 164-174.

Yousuf, M. (2016). Niches in the networked media ecosystem: Functionalities, gratifications, and a typology of online news and informational media. [Doctoral dissertation, University of Oklahoma, USA]. SHAREOK. https://shareok.org/handle/11244/33708

Zar, J. H. (1999). Biostatistical analysis: Pearson Education India.

Zhang, X., \& Albarran, A. B. (2018). The global and the local. Journal of Globalization Studies, 9(2), 32-49. 
